\title{
LAS GRANDES REFORMAS AL DERECHO DE FAMILIA EN EL PROYECTO DE CÓDIGO CIVIL Y COMERCIAL ARGENTINO 2012
}

\author{
IMPORTANT AMENDMENTS TO THE FAMILY LAW IN THE BILL TO \\ REFORM THE CIVIL AND COMMERCIAL CODES OF ARGENTINA 2012
}

Graciela Medina ${ }^{1}$

\section{RESUMEN}

El Anteproyecto de unificación del Código Civil y Comercial redactado por la comisión designada por Decreto Presidencial $N^{\circ} 211$ del 23 febrero del 2011 contiene profundas reformas al Derecho de Familia que nos proponemos enunciar en este artículo.

Las más importantes son: El cambio en las denominaciones tradicionales. La disminución explícita de los deberes personales del matrimonio, con la reducción del deber de fidelidad a deber moral. El divorcio incausado. La regulación del concubinato al que se denomina unión convivencial. El establecimiento de deberes para los padres por afinidad. La aceptación de un tercer tipo de filiación. La filiación por voluntad procreacional. La posibilidad de pactar el régimen patrimonial matrimonial. El establecimiento de un nuevo procedimiento de adopción, más complicado, con más actores y con gran preponderancia del órgano administrativo. La regulación del procedimiento de familia.

Palabras Claves: Familia, Derecho de Familia, Reforma al Código Civil, Reformas, Cambios en el derecho de Familia, Adopción, Régimen Patrimonial del matrimonio, Unión Convicencial, Divorcio, Filiación.

\section{ABSTRACT}

The Bill to unify the Civil and Commercial Code drafted by the commission appointed by Presidential Decree $N^{\circ} 211$ of February 23, 2011 contains major reforms to Family Law, which we propose to list in this article.

The most important ones are: changing traditional names. The explicit dwindling of personal responsibilities of marriage, including the weakening of the duties of fidelity

\footnotetext{
1 Presidenta de la Cámara Nacional de Apelaciones Civil y Comercial Federal de la República de Argentina Profesora de Derecho Civil de la Universidad de Buenos Aires UBA.

Fecha de recepción : 21 deagosto de 2013

Fecha de aceptación : 10 de setiembre de 2013
} 
and moral support. No-fault divorce. The regulation of cohabitation called domestic partnership. The establishment of responsibilities of step-parents. The acceptance of a third type of filiation. Filiation of a child born of assisted procreation. The possibility of prenuptial agreement. The establishment of a new, more complex, adoption procedure, with more actors and prevailing role of the administrative body. Family proceedings rules.

Key Words : Family. Family Law. Civil Code Reform. Reforms. Amendments to the Family Law. Adoption. Marital Property Regime. Domestic Partnership. Divorce. Parentage.

\section{INTRODUCCIÓN}

El proyecto del Código Civil y Comercial, redactado por la comisión designada por Decreto del Poder Ejecutivo $\mathrm{N}^{\circ} 211$ del 23 de febrero de 2011, contiene profundas modificaciones al Derecho de Familia. En este artículo nos proponemos señalar cual fue el método utilizado, justificar la necesidad de una reforma integral al Derecho de Familia, analizar cuál es la filosofía del proyecto y describir brevemente los cambios mas importantes.

\section{LA NECESIDAD DE LA REFORMA INTEGRAL Y ORGÁNICA DEL DERECHODEFAMILIA}

El Derecho de Familia requiere de una forma integral y orgánica por cuatro razones fundamentales. En primer lugar, porque ha quedado desactualizado con respecto a los cambios sociales que se han operado en la sociedad; en segundo Iugar, porque hay que adecuarlo a la Constitución de 1994, que es posterior a muchas de las normas básicas; en tercer lugar, porque las reformas parciales introducidas fundamentalmente por la Ley de Divorcio Vincular 23515, la Ley de Matrimonio Igualitario 26.618, la Ley de Mayoría de Edad, la Ley de Salud Mental, Ia Ley de Género, la Ley 26.48 de Protección Integral y la Ley 26.061 de Protección a Niños, Niñas y Adolescentes, han producido desarmonías sistémicas y desajustes legislativos que generan problemas que son respondidos por una jurisprudencia contradictoria lo que produce inseguridad jurídica; en cuarto lugar, porque el régimen patrimonial del matrimonio nunca ha sido integralmente reformado $y$ ha quedado completamente inarmónico. Vamos a tratar de explicar las cuestionas que fundamentan la necesidad del cambio. 


\section{DESBATUALZACIÓN DEL DERECHO DE FAMILIA CON FESPECTOA A REALIDAD.}

Ta famila es ma institución dinámica y evolutiva y el derecho que la regula debe atender a la realidad que se presenta y dar encuadre a las situaciones ¿tutuales. En este sentićo, el Derecho de Familia argentino está desactualizado $y$ ho constituye una herramienta eficaz para dar respuesta a los problemas gue las ́amilias ilenen, ni para proveer un marco regulatorio a las formas cotno etlas se presentan.

Es imprescindile que se aggiome y que se regulen instituciones y situaciones shenciadas.

Basin dos ejemplos para demostrar la necesidad de una reforma integral: En princex lugara, el Código no contempla las técnicas de fecundación asistida y silencia toco tipo de respuestã sobre la filiación que se origina a partir de estas practicat abohitamente extendidas en la sociedad argentina, que cuenta con aspecinlistas y cimicas queson reconocidas mundialmente por su experticia.

Mentres log Tribunales deciden, a lo largo y ancho del país, quién debe

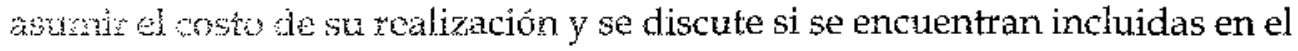
MM, orderamiento itsprivatista, nada dice sobre las relaciones de Fotrraridad que se producer con su utilización, así como la falta de respuesta a as y de la matemídad cuando se utilizan técnicas de concepción médicamente acibida es vin claro indicativo de la necesidad de la reforma que debe dar so. mción é esta realidad familiar que no se contempla ni en el Código Civil, ni ex leyes compiementarias, y que originó que en el Proyecto se regule la filactors por volutad procreacional.

Eegundo ejerrolo de la desacualización normativa viene dado por la carencia de cualquier tipo de regulación de la familia recompuesta o ensemblada, que nace, a partir de los segundos matrimonios de los cónyuges. Fospuses de más de casi un cuarto de siglo de vigencia de la ley de divorcio vincuaz' cientos de miles de familias se han constituido a raíz de las segundas rupcias do los divorciados sin que el derecho contemple esta situación, ni de repuestas a sus dificultades específicas.

Estita ewolución social familiar, -a la que podemos agregar la de las familias surgidas de las aniones de hecho-, fuera de toda norma jurídica, justifica una netcreantegral del Derecho de Familia. 


\subsection{NECESIDAD DE ADECUACTÓN AL PLEXO CONSTITUCIONAL}

La mayoría de las instituciones del Derecho de Familia han sido reguladas con anterioridad a la vigencia de la Constitución del año 1994 que incorpora a su texto los tratados constitucionales vigentes hasta ese momento; por ende, las disposiciones constitucionales y supraconstitucionales de los tratados de los Derechos Humanos deben ser incorporadas al Código para hacer que éste sea congruente con ellas y evitar que los jueces deban dictar la inconstitucionalidad de las normas civiles desajustadas al Derecho Constitucional, como ocurre, por ejemplo, con la negativa de la legitimación de la concubina para reclamar el daño moral ante la muerte de su conviviente, para citar uno de los múltiples casos que se dan en los Tribunales.

\subsection{DESARMONIA LEGISLATIVA PROVOCADA POR LAS REFORMAS PARCIALES.}

Múltiples fueron las reformas parciales que sufrió el Derecho de Familia, directa o indirectamente, desde la sanción del Código Civil hasta nuestros días. Entre las realizadas en el siglo XXI cabe mencionar la Ley $\mathrm{N}^{\circ} 26.061$ de Protección Integral de Niños, Niñas y Adolescente, la Ley No 26.485 de Protección Integral a las Mujeres, que completa la política antidiscriminatoria respecto de las mujeres y tiende a su tutela efectiva frente a las distintas formas de violencia a que estas se encuentran sometidas en la sociedad contemporánea, la Ley $\mathrm{N}^{\mathrm{j}} 26.579$ que determina la mayoría de edad a los 18 años, la Ley $\mathrm{N}^{\circ} 26618$ que permite el matrimonio entre personas de igual sexo con iguales efectos que el matrimonio entre personas de diferente sexo, la Ley No 26.743 de Identidad de Género y la Ley No 26.742 de Muerte Digna.

Estas leyes contemplan reformas en instituciones qute no están pensadas para ellas, y generan múltiples incongruencias que requieren que el intérprete continuamente acuda a ficciones o declaraciones de inconstitucionalidad para vencer las desarmonías. Para mostrar algunas de las contradicciones basta con recordar las suscitadas por la Ley 26618 que establece que no deben existir desigualdades entre los matrimonios homosexuales y heterosexuales; sin embargo, como la ley de matrimonio entre personas de igual sexo se ha insertado en un sistema en el que las nupcias estaban persadas para las parejas heterosexuales, existen divergencias; como por ejemplo, las diferencias en las presunciones de paternidad matrimonial que no pueden aplicarse en forma idéntica a las parejas de lesbianas y a las parejas heterosexuales, porque no se puede aplicar a una relación lésbica la presunción de paternidad del marido de la madre, ya que no hay ningún padre. 
En definitiva, la falta de determinación clara de los lazos filiatorios que tiene el hijo biológico de uno de los cónyuges homosexuales, nacido durante el matrimonio, con el otro cónyuge, y la diferente regulación del "nombre de familia" establecido solo para los matrimonios homosexuales y no para los heterosexuales, más las distintas formas con que ambas uniones deben pagar el impuesto a las ganancias y a bienes personales, acredita la necesidad de una regulación integral del Derecho de Familia que regule los matrimonios del mismo sexo en todas sus instituciones o que cambiara sus instituciones a la realidad de un matrimonio sin diversidad sexual.

En definitiva, cada una de las leyes que antes mencionamos producen desarmonías al introducirse en un sistema que había sido construido con otra realidad; ello justifica un cambio que armonice las nuevas soluciones en forma integral.

\subsection{CARENCIA DE CUALQUIER REFORMA INTEGRAL DEL RÉGIMEN PATRIMONIAL DEL MATRIMONIO.}

Advertimos que, a diferencia de los regímenes de patria potestad y de divorcio que fueron íntegramente modificados por distintas leyes, el régimen de bienes del matrimonio del Código originario nunca fue integralmente cambiado, sino que sufrió cambios parciales, que se fueron superponiendo con el correr de los años.

Como resultado de las reformas parciales que sufrió a lo largo de los 140 años, el régimen patrimonial del matrimonio se presenta confuso, a tal punto que ni siquiera se sabe bien cual era su denominación. Por otra parte, las normas que lo regulan están dispersas en leyes ajenas al código, y se duda de la vigencia de muchas de las disposiciones.

El sistema es incompleto y dificultoso ya que no existen disposiciones claras ni con respecto al régimen de deudas entre los cónyuges al momento de la disolución del matrimonio, ni con referencia a las normas a aplicar a la indivisión post comunitaria, ni al sistema de las recompensas. Las soluciones se estructuran de acuerdo a una jurisprudencia que se consolida muy lentamente, con las consiguientes inseguridades jurídicas, producida por las divergencias en las diferentes jurisdicciones.

En el año 2012, el régimen de bienes en el matrimonio tiene las siguientes características: 
a) Está contemplado en un capítulo que se titula "Sociedad conyugal", con lo cual lo primero que correspondía hacer era explicar que no se trataba de una "sociedad".

b) Regula la "dote" de la mujer, siendo que la mujer casada carece de dote alguna; por ende, hay que darle a la denominación "dote" un significado diferente e interpretar que toda alusión a "dote" equivale a "bienes propios de la mujer".

c) No existen normas claras sobre indivisión post comunitaria.

d) El sistema de recompensas es confuso, lo que genera múltiples inconvenientes en un país signado por la inestabilidad económica y grandes crisis inflacionarias.

e) No hay disposiciones que aclaren cuál era el carácter de las crías de ganado en una República de característica ganadera. ${ }^{3}$

f) Las disposiciones sobre la propiedad intelectual son insuficientes, no hay regulación alguna sobre las marcas, ni sobre las patentes en un mundo signado por los avances tecnológicos. ${ }^{4}$

g) Hay discordancias de criterios sobre la existencia de bienes gananciales de "carácter dual" lo que genera inseguridades en la administración y disposición en bienes adquiridos con dinero propio y ganancial. ${ }^{5}$

h) No se encuentra aclarado si para disponer de las acciones nominativas y Ias participaciones se requiere el asentimiento conyugal, cuando el $90 \%$ del capital se encuentra en sociedades de familia.

i) Se duda si a las acciones de fraude entre cónyuges se les aplicaba las normas de fraude entre los acreedores.

j) No se sabe claramente cuáles son las normas que regulan las deudas entre los conyuges al momento de la disolución de la sociedad conyugal.

En definitiva, si bien la labor de la jurisprudencia clarifica la cuestión, lo cierto es que se requiere una adecuación del régimen de bienes entre los cónyuges coherente con el sistema patrimonial imperante y con la situación

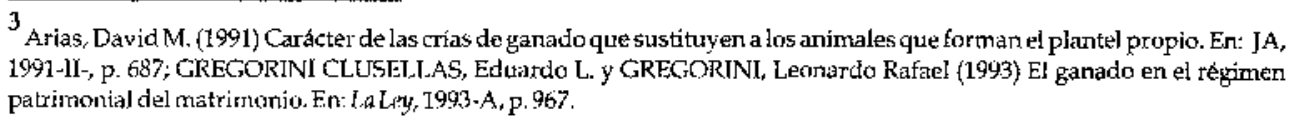

4 Guastavino, Elías P. "Los derechos intelectuales y la comunidad de bienes del matrimonio". ED, 21-430; MEDLNA, Graciela (1998) Derecho de autor y régimen patrimonial del matrímonio. En: La Ley, 1998-E, 1022; MAZZINGHI (h.), Jorge Adolfo (1984) La calificación de los bienes de los conyuges y el ejercicio de un pacto de retroverata. En: La Ley, [984-A, 182; Sociedad Conyugal. Origen del dinero. Obra literatia. Autoria. Producido garancial. Consulta notarial. En: Revista de! Notariado, N 814 .

5 Allende, Alberto G. “FI bien de natturaleza mixta en la socieclad conyugal (importancia para el dexecho notarial de su calificación." ED, 28-885; ALLENDE, Alberto C. (1993) Concurrencia de aportes propios y gananciales adquisitivos de dominio. En: Revisfia del Notariado $N^{\circ}$ 834; ALLENDE, Luis Maria (1986) Los liamados bieners mixtos en la sociedad conyugal, En: Revista del Notariado $\mathrm{N}^{\circ}$ 806; CACCIARDI, Norberto; CATUREGLI, Susana; COLDFARB, Marta; NOSTRO DE SEGHETTL, Ni]da; PELOSI, Horacio; SEGHETTI, Roberto y SLIMOVICH de BURSTEIN, Rita (1993) Problemática de 
de la mujer, protegida por múltiples convenciones internacionales que hacen insostenible referencias a la dote de la "mujer casada".

\section{LA FILOSOFÍA DEL PROYECTO}

Por las consideraciones antes enumeradas, creemos que una reforma integral y armónica del Derecho de Familia es imprescindible. Lo que se discute en la comunidad son las características puntuales de las reformas adoptadas por la Comisión de Reformas designada por Decreto Presidencial que, en definitiva, responden a la elección de una política legislativa y que, a su vez, responde a una determinada filosofía. En este sentido, cabe enumerar cuales son las bases filosóficas de la reforma.

La filosofía del proyecto se caracteriza por:

3.1 Respeto por la autonomía de la voluntad en la determinación de las relaciones personales y patrimoniales, con una consiguiente disminución de las pautas imperativas que siempre caracterizaron al Derecho de Familia. De allí la aceptación de: la voluntad procreacional, la posibilidad limitada de elección del régimen patrimonial matrimonial, de la autorregulación de las uniones convivenciales, la delegación de la Responsabilidad parental y de la gestación por otro.

La autonomía privada o capacidad de autorregulación se ve notoriamente ampliada en el proyecto, a tal punto que en el Derecho de Familia ya no cabe afirmar que la imperatividad es la regla y, la autonomía privada, la excepción.

En numerosos supuestos conflictivos, el sistema proyectado reclama ante todo un acuerdo entre los interesados; como, por ejemplo, para acceder al divorcio se requiere obligatoriamente presentar un convenio regulador de los intereses familiares, y para regular la unión convivencial, se prefieren la celebración de pactos de convivencia (Arts. 513,514 y 515). 


\subsection{Imperatividad de las normas de Derecho de Familia relativas a la responsabilidad parental}

La ampliación de la capacidad autonormativa a la que hiciéramos referencia en el apartado anterior, se da fundamentalmente en las relaciones de los convivientes y los cónyuges entre sí.

En principio, el proyecto permite que los cónyuges puedan configurar el contenido de su matrimonio. Ello así, establece un reducido número de deberes y derechos obligatorios, y permite que los contrayentes fijen las restantes pautas que regularán su matrimonio.

En las uniones convivenciales ocurre una situación similar, ya que los convivientes tienen un amplísimo poder para autorregular sus deberes y derechos tanto personales como patrimoniales mediante los pactos de convivencia los que se encuentran limitados solo por la imposibilidad de no ser contrarios al orden público, ni al principio de igualdad de los convivientes, ni afectar los derechos fundamentales de cualquiera de los integrantes de la unión convivencial.

Por el contrario, el régimen propuesto no da igual capacidad de libertad a la autonomía de la voluntad en orden a la responsabilidad parental, ni a las normas relativas a la filiación, en estos supuestos, los padres no pueden decidir cuáles son los deberes con respectos a sus hijos en contra de las normas legales ni por debajo de ellas.

En definitiva, en el sistema proyectado, la mayor parte de las disposiciones legales con respecto a los hijos y a las personas con discapacidad se caracterizan por ser normas de carácter imperativo.

\subsection{Capacidad progresiva}

Otro de los principios que ha recogido el proyecto es el de la capacidad progresiva de las personas que se ve plasmado fundamentalmente en las normas del Derecho de Familia.

El sistema actual del Código Civil relativo a la capacidad es perfectamente válido para la capacidad patrimonial, esto es, para determinar la aptitud del sujeto para celebrar actos jurídicos y en particular contratos. Es un sistema que funciona a la perfección (o casi) para dotar de seguridad a las partes de 
que quienes están contratando pueden hacerlo. Pero este sistema entra en crisis cuando se trata de determinar la capacidad del sujeto para el otorgamiento de otro tipo de actos, en particular, los de disposición de su propio cuerpo y de sus derechos personalísimos. Al menos, con relación a estos actos, es por ello, que el sistema proyectado recepta una capacidad progresiva o competencia cuya determinación puede hacerse en función de fraccionamientos o en función del discernimiento de cada sujeto individual.

En este sentido, el proyecto otorga una capacidad diferenciada a los niños que a los adolescentes, dándoles a éstos mayor autonomía en orden a las decisiones personales e inclusive otorgándoles capacidad jurídica plena en algunos supuestos como por ejemplo: en la adopción. Los adolescentes pueden iniciar una acción autónoma para conocer sus orígenes.

Por otra parte, en el sistema propuesto se propugna reiteradamente el derecho del niño, niña o adolescente a ser oído y a que su opinión sea tenida en cuenta según su edad y grado de madurez.

\subsection{Respeto y regulación de los diferentes modelos de familia y neutralidad de las soluciones.}

Una de las pautas básicas en la elaboración del nuevo Derecho de Familia ha sido el respeto por todas las formas de familia. Por ello, se ha elaborado un sistema lo suficientemente neutro para acoger a los opuestos modelos familiares que conviven en la sociedad del siglo XXI, como lo son la familia nuclear, la familia monoparental, la familia ensamblada o recompuesta, la familia homosexual, la familia matrimonial y la familia extramatrimonial.

\section{LAS CRÍTICAS AL SISTEMA. EL PORCENTAJE DE RECHAZOS, LAS ENCUESTAS.}

Las críticas que se han realizado al sistema no tienen relación con la necesidad de una reforma integral y armónica, ni con las líneas filosóficas que antes hemos enunciado sino que son críticas concretas a las soluciones adoptadas; es decir, que se cuestiona la forma como los grandes principios, que no se discuten, se concretizan en las normas positivas.

Así nadie discute, ni cuestiona, que se debe aumentar el margen de libertad en la regulación de las relaciones personales, ni que los niños tienen derecho a ser oidos, ni que es diferente la capacidad de un menor de 10 años a un joven de 17 
años, ni la necesidad de respeto a los diferentes modelos familiares. Lo que se cuestiona es la forma cómo se pretende llevarlo a cabo y lo radical de las soluciones propuestas.

De ello da cuenta una encuesta realizada por Diario Judicial, relativa a la conformidad con la reforma proyectada, que dio como resultados, los siguientes:

El $21.5 \%$ contestó que: "Es un cambio necesario. En reglas generales estoy de acuerdo con la iniciativa."

Mientras que el $19.9 \%$ respondió: "No hay nada que reformar. El Código actual es perfectamente útil."

La mayoría del $58.6 \%$, se inclinó por afirmar: "Creo que hay que reformar el Código pero hay que revisar más algunos puntos conflictivos".

Es decir, que no hay consenso en la forma cómo se resuelven los temas conflictivos que son justamente los relacionados con el Derecho de Familia.

Los aspectos cuestionados son los referidos a la flexibilización de los deberes derivados del matrimonio, la supresión de la separación como forma de dar fin al matrimonio, la admisión de la gestación por otro, la mirada desfavorable cómo se regula la adopción, y la solución proyectada para el concubinato, denominado unión convivencial.

En definitiva, lo que se cuestiona es la falta de coherencia del sistema que propugna la libertad y la autodeterminación en las relaciones personales familiares, permitiendo la existencia de un matrimonio sin convivencia y sin deber jurídico de fidelidad, al tiempo que retacea las formas de disolución del matrimonio prohibiendo la separación como forma de dar fin al matrimonio, eimpidiendo toda forma de unión libre entre dos personas.

Señala Guillermo Borda(h) "Tanto se predica y se habla de la importancia de la "democratización de la familia" de la "protección integral de la familia" del "avance de la autonomía de la voluntad en el derecho de familia", que "el proyecto amplía la aptitud de decisión a los integrantes del matrimonio", que "la injerencia estatal tiene límites", y sin embargo, en contra de todas estas argumentaciones se impide que los cónyuges puedan requerir solamente la separación personal, sin disolución del vínculo. ¿Cuál es la razón? ¿Qué derecho se vulnera al no disolverse el vínculo? ¿Qué razón existe para 
impedir que los cónyuges se separen, dividan sus bienes, pero mantengan el vínculo matrimonial? ¿Por qué razones no puede permitírseles mantener su vocación hereditaria o el derecho a recibir alimentos de por vida si así lo convinieran y que estando divorciados vincularmente no lo pueden hacer?" ${ }^{\text {. }}$.

Advierte Julio Rivera -con la agudeza que lo caracteriza- que realmente le resulta difícil identificar cuál grupo cultural, social o religioso de los que comparten nuestro suelo propone esta "visión" del matrimonio.

"Pero aún suponiendo que este no es un modelo matrimonial de probeta, sino que responde a alguna necesidad o reclamo social de algún - hasta ahora ignorado por mí - grupo social, se trataría, según anuncian los Fundamentos, de regular una serie de opciones".

"Pero entonces, ¿por qué no aparecen tales "opciones" en los textos proyectados? Por el contrario: hay un solo modelo de matrimonio, y se nulifica la renuncia de cualquiera de los cónyuges a la facultad de pedir el divorcio, teniéndose por no escrito el pacto que restrinja la facultad de solicitarlo (Art. 436)".

"Porqué si queremos dar opciones de vida propias de una sociedad pluralista no pensamos en reales alternativas. Como por ejemplo, que los contrayentes puedan optar por contraer: (i) un matrimonio indisoluble ${ }^{7}$; (ii) un matrimonio susceptible de divorcio en razón de ciertas causas y solo susceptible de ser promovido por el inocente; o (iii) un matrimonio con ciertas obligaciones personales voluntariamente asumidas por las partes, más extensas que las previstas en el matrimonio ordinario".

"Si bien podría cuestionarse la constitucionalidad de la opción por un matrimonio liso y llanamente indisoluble no parece que ello pudiera

lus llamados bienes mixtos en el regimen patrimonial matrimunial. Análisis del Plenauiu "Sanz". En: Revista del Nofariado No 834; CAPPARELLI, julio César (1992) 'Trascendencia de un reciente plenario sobre calificación de bienes del matrimonio. Ér: Revista del Notariado $N^{\circ} 830$; CERRA, Silvana (2010) Calificación y prueba de los bienes. Aplicación a un supuesto especial: adquisición de un inmueble mediante el empleo de fondos de carácter propio y ganancias. En: Revista de Derecho de Familin y de las Personas - RDFYP, p. 50; FERRARI Ceretti. Francisco (1993) Bienes en parte propios y en parte gananciales en el patrimonio de la sociedad conyugal. En: Revista del Notariado No 833; LABAYRU, José Maria (1993) ¿Puede ser un bien propio y ganancial a la vez? En: Revista del Notariado N 834; MENDEZ COSTA, Maria Josefa, (1990) Condomínio y cosas garanciales indivisas: un aspecto de la cuestión". En : La Ley, p. 322.

${ }^{6}$ Borda, Guillermo (2012) Las relaciones de familia en el proyecto del Código Civil y Comercial, En: Rerristu de Dexecho de la Familia y de las Personas - RDFyP, Julio p. 40.

${ }^{7}$ Sobre el punto v.; CHIESA, Pedro José Maria, El derecho a la protección constitucional de las opciones matrimontales definititus. Tesis doctoral, Universidad Nacional de Cordoba, Córdoba, 2010; De Fuenmayor, A. (1992) Derecho de contraer matrimonio civilmente indisoluble. En: Estudios de Derecho Civil, Navarra. 
extenderse a las otras hipótesis. En el marco de un sistema constitucional como el de Estados Unidos, de obvia vinculación con nuestro régimen constitucional, ciertos Estados admiten el denominado covenant marriage (matrimonio blindado o matrimonio alianza) en el que los cónyuges asumen determinadas causas de ruptura y el compromiso formal de superar las eventuales dificultades que pudieran amenazar la continuidad de la unión. Se trata de iniciativas legales orientadas al fortalecimiento del matrimonio que permiten la plasmación positiva de la libertad de los cónyuges comprometerse y constituyen una alternativa a los divorcios incausados; así lo señala el mismo título de un trabajo publicado hace ya unos años: ${ }^{\prime} \mathrm{El}$ covenant marriage como alternativa a las non fault divorces". 8

No reiteraremos las críticas al sistema de filiación ideado; sobre el tema, nos remitimos a los múltiples trabajos publicados, por Mizrahi, ${ }^{9}$ Sambrizzi, ${ }^{10}$ Berebere Delgado ${ }^{11}$, Sojo ${ }^{12}$, Laje ${ }^{13}$ y Jorge Azpiri ${ }^{14}$ que en general cuestionan la aceptación de los convenios de gestación porque implican aceptar la comercialización del cuerpo de la madre y del hijo.

\footnotetext{
8 Cañivano, Miguel Angel, (2002) El covenant marriage como alternativa a los tun fault divorces, En: Rroista de Derecho Privado, Madrid, p. 166. Este autor indica que a la época de su trabajo tenían consagrado este tipo de matrimonio Louisiana, Arkansas y Arizona; en Michigan y en Lowa, leyes semejantes se encontraban en trámite parlamentario. Las leyes indicadas definen al covenant marriage como un "matrimonio convenido entre un hombre y una mujer, que comprenden y están de acuerdo en que el matrimonio es una relación para toda la vida. Los contrayentes, en este caso, han recibido un especial asesoramiento sobre la naturaleza delmatrimonio y sus responsabilidades. Solo cuando haya habido un completo y total incumplimiento del compromiso adquirido en virtud del converio marital, podrá la parte agraviada obtener una declaración para que el matrimonio no sea legalmente reconocido por más tiempo" (traducción de Cañivano, ob. Cit., p. 170; el tex to en inglés de la New Louisiana Covenant Marriage Act, en el mismo lugar citado, nota 14).
}

${ }^{9}$ Mizrahi, Mauricin Luis (2012) Observaciones al Proyecto en materia de filiación. En: Revista de Derecho de Familia y de las Persomas- RLEyPjudio. Edictión Especial: Análisis del Proyecto del Codigo Civil y Comerciał de ta Nación, p. 124.

\section{0}

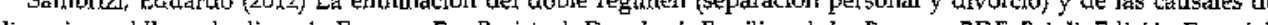
divorcio, y el llamado divorcio Express. En: Revista de Derecho de Familia y de las Personts RDFyp, juli. Edición Especial: Análisis del Proyecto de Código Civil y Comercial dela láación, p. 90.

11

Berbere Delgado, forge (2012) El Derecho Filial en el proyecto de Código Civil y Comercial - Nuevos paradigmas. En: Revista de Derecto de Familia y de tas Personas $-R D F_{y} P_{r}$ julio. Edición Especial: Análisis del Proyecto del Codigo Civil y Comercial dela Nacion, p. 14k.

12 Sojo, Lorenzo (2012) Filiación post mortem en el Proyecto del Código Civil y Comercial. En: Revista de Derecho de Fantilia y de las Personas RD FyP. julio. Edición Especial: Análisis del Proyecto del Código Civil y Comercial de la Nación, p. 134.

13.

Laje, Alejandro (2012) Las derivaciones inmediatas y medialas del vínculo matemo-filial por el Proyecto. En: Revista de Derecho de Funilia y de las Persmas RDFyPr julio. Edición Especial Análisis del Proyecto del Código Civil y Comercial de la Nacion, p. 136 .

14 Axpiri, forge (2012) La filiación en el Proyecto de Código Civil y Comercial. En: Revista de Derecho de Familia y de las Persontas RDFuP, julio. Edición Especial: Análisis del Proyecto de Codigo Civil y Comercial de la Nacion, p.115. 
A ello se suma las críticas al complicadísimo sistema de adopción que se ha ideado con la supresión, en el Proyecto, de las normas relativas a la adopción internacional que se encontraban, y que al menos daban seguridad, a los argentinos que adoptaban en países extranjeros.

Por nuestra parte, pensamos que el proyecto en estos aspectos, requiere un consenso mayor que el que cuenta hoy en día.

A continuación enumeramos y reseñaremos brevemente los cambios mas importantes que se proponen.

\section{LOS CAMBIOS MÁS IMPORTANTES}

En este punto nos proponemos enunciar los diez cambios más trascendentes en estas materias, los cuales son:

1. El cambio en las denominaciones tradicionales.

2. La disminución explícita de los deberes personales del matrimonio, con la reducción del deber de fidelidad a deber moral.

3. El divorcio incausado.

4. Las compensaciones económicas.

5. La regulación del concubinato al que se denomina unión convivencial.

6. El establecimiento de deberes para los padres por afinidad.

7. La aceptación de un tercer tipo de filiación. La filiación por voluntad procreacional.

8. La posibilidad de pactar el régimen patrimonial matrimonial y los cambios al régimen de comunidad.

9. El establecimiento de un nuevo procedimiento de adopción, más complicado, con más actores y con gran preponderancia del órgano administrativo.

10. La regulación del procedimiento de familia.

\section{EL CAMBIO EN LAS DENOMINACIONES}

El primer cambio que advierte, quien lee el proyecto por primera vez, aunque no el más significativo, es el cambio en las denominaciones clásicas del Derecho de Familia por otras más progresistas y consideradas "políticamente correctas", aunque en muchos casos alejadas por completo del uso común de la población y de la generalidad de los abogados. 
Al cambio en los nombres se agregan, por una parte, nuevas denominaciones para nuevas categorías de relaciones familiares; $y$, por otra, la aparición de relaciones sociales existentes en la sociedad pero que no tenían hasta el momento efectos jurídicos, como lo es el "allegado", el "amigo íntimo", el "referente afectivo" o el "cuidador".

La justificación para cambiar la nomenclatura es evitar en algunos casos el contenido discriminatorio que el significado etimológico de los términos contienen, como en el caso de "concubinato" o de "patria potestad"; la intención es buena, pero el problema reside en que ellos tienen amplia "carta de ciudadanía" en el mundo jurídico, están perfectamente delimitados y el alcance de su contenido no ofrece ninguna duda porque han sido construidos y elaborados durante décadas.

Cabe señalar que la etimología de los términos se ha desprendido de su sentido; por ejemplo, el término "salario" etimológicamente quiere decir "pago con sal" y nadie se le ocurre que el salario se debe pagar con sal.

En igual sentido, la etimología de la palabra "patria potestad" nada tiene que ver con el sentido que se le ha dado a ella a partir de la Ley 23264 que ya tiene 29 años de vigencia.

Cabe recordar que cuando se discutía la Ley de matrimonio igualitario, quienes se oponían a él señalaban que la etimología de la palabra matrimonio solo permite referirse a la unión entre un hombre y una mujer, mientras que sus sostenedores afirmaban en forma coincidente que la etimología de una palabra no constituye de por si una razón normativa para reconocer o desconocer un derecho. ${ }^{15}$

Así, Solari señala: "Que si bien muchas veces se incursiona en la etimología de un término, debemos advertir que las instituciones jurídicas evolucionan y cambian de conformidad con las sociedades y los tiempos en que son aplicadas. En este contexto muchas veces la etimología de una palabra va perdiendo su esencia y alcance que tenía en algún momento o en su origen. Muchos ejemplos pueden servir para ejemplificar tal aserto; en el Derecho de Familia, encontramos términos jurídicos que tienen que ver con su origen histórico, patria potestad, filiación, apellido marital: entre otros" ${ }^{16}$

15 Clerico, Laura (2011) El matrimonio igualitario igualdad y-o autonomía En: Matrimonio entre personas dal mismo sexo.

16 Ley 26.618. Directores SOLARI, Néstory VONOPIELA, Carolina, Ed. LL, p.53.

Solari, Néstor (2011) Aspectos axiológicos de la ley Et: Matrimonio entre personas del mismo sexo. Ley 26.618. Directores SOLARl, Néstor y VON OPIELA, Carolina, Ed. LLt p. 207. 
En definitiva, la etimología de los términos no justifica los cambios propuestos.

Los nuevos términos lucen como no discriminatorios, pero carecen totalmente de definición en cuanto a su contenido y alcance, y en muchos casos causan estupor ante su sola mención; así por ejemplo, no se conoce exactamente cual es la "extensión" de la "familia extendida", ni tampoco cual es el concepto correcto de "referente afectivo", ni de "voluntad procreacional". Todos ellos, términos que el intérprete se verá obligado a definir, delimitar, limitar y rellenar de contenido jurídico.

Algunos de los cambios en las denominaciones son las siguientes:

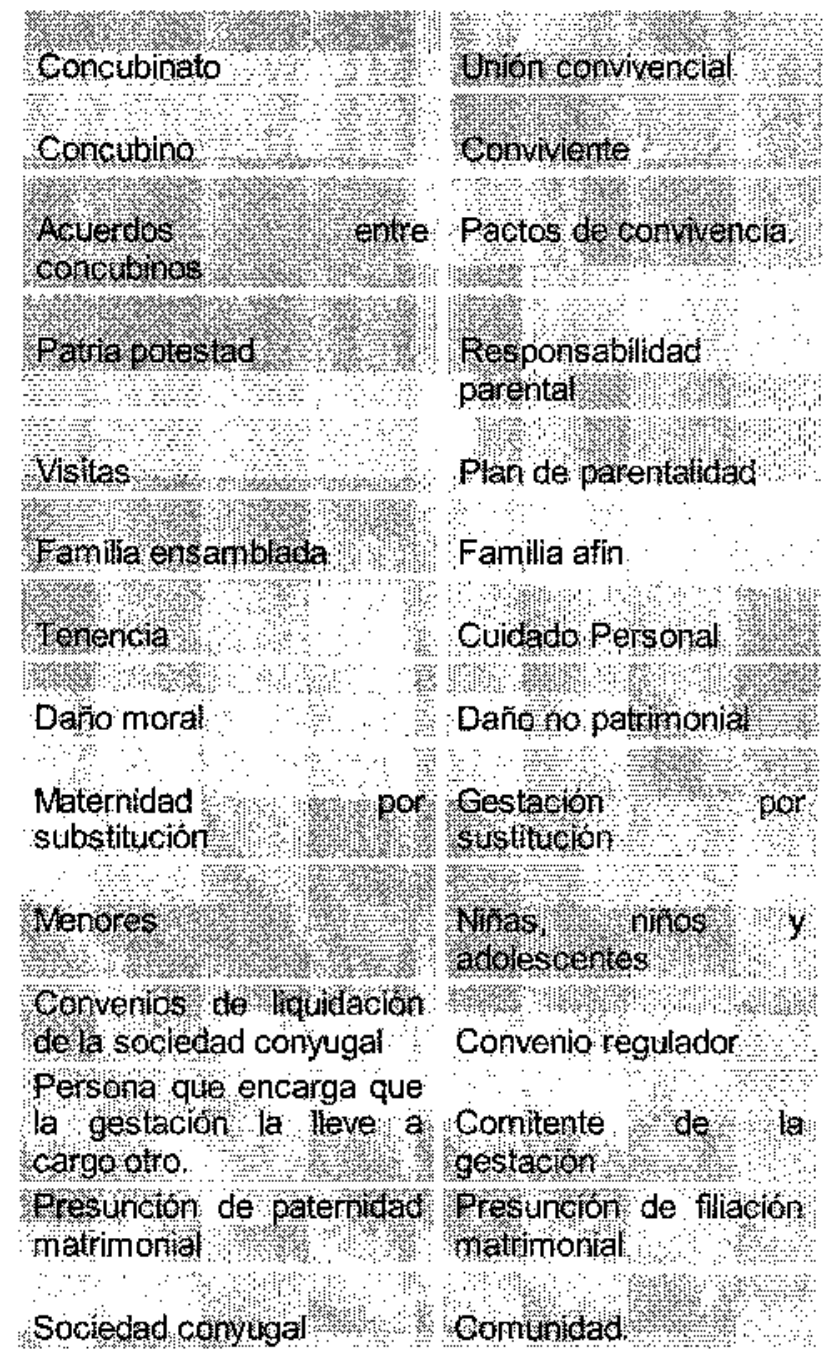


También nos encontramos con nuevos nombres y nominaciones que no encontrábamos en el ámbito jurídico, como:

\begin{tabular}{ll} 
- & Voluntad Procreacional, \\
- & Pensión Compensatoria, \\
- & Pactos de Convivencia \\
- & Referente Afectivo \\
- & Allegado \\
- & Capacidad intima \\
- & Persona protegidaida \\
\hline
\end{tabular}

\section{LA DISMINUCIÓN EXPLICITA DE LOS DEBERES DEL MATRIMONIO.}

Se acepta el matrimonio entre personas de igual y distinto sexo y se establece como principio general que no se pueden establecer distinciones entre ambos tipos de nupcias. ${ }^{20}$

Se suprime el deber de cohabitación y el de fijación de un domicilio conjunto, y se establece que el deber de fidelidad es sólo moral.

En un primer proyecto, se había pensado en suprimir totalmente el deber de fidelidad matrimonial, porque se pensaba que este deber de fidelidad matrimonial no era estrictamente jurídico y debía quedar reservado al ámbito privado.

17 Artículo $711^{\circ}$.- Testigos. Los parientes y allegados a las partes pueden ser ofrecidos como testigos. Artículo $59 .-$ Consentimiento informado para actos médicos. Si el paciente no está en condiciones físicas o psiquicas para expresar su voluntad al tiexnpo de la atención médica ni la ha expresado anticipadamente, el consentimiento puede ser otorgado por el (...) allegado que acompañe al paciente.

18

Artículo $108^{\circ}$ - Pruhibiciones para ser un tutor dativo. El juez no puede conferir tutelia dativa: (...)

b) a las personas con quients mantiene amistad intima.

, hijos menotes de éste.

20

20 Para un mayor desarrollo del tema relativo a los deberes natrimoniales ver mi artículo en esle mismo libro "Matrimonio y Disolucion" sobre todo los puntos 1 Requisitus del matrinotsio. 3.1 Fal ta de Salud Mental.3.2 Desaparece el impedimento de sordomudez. 3.3. La impotencia deja de ser causa de nulidad de matrimonio. 4. Los deberes y derechos matrimoriales. 4.1 Caracteres de los deberes y derechus de1 matrimonio. 4.1.1 Son deberes mínimos. 4.1.2. Son deberes imperativos. 4.1.3. Son deberes reciprocos. 4.1.4. Son incoercibles - salvo el deber de alimentos. 4.2. l cumbio en el sentido de los deberes derechos matrimoniales a partir del divorcio incausado. 4.3. Funciún actual de los deberes derechos matrimoniales. 4.4. La sanción por el incumplimiento. 
En los fundamentos de esta primera versión del proyecto se señalaba cómo se establecía un divorcio incausado, y que el incumplimiento del deber de fidelidad no generaba consecuencias jurídicas y por eso, no se lo regulaba.

La falta del deber de fidelidad en el matrimonio fue objeto de críticas desde todos los sectores de la doctrina jurídica, ya que por más que el divorcio se establezca en forma incausada, la fidelidad es la esencia matrimonial y hace a su causa fin; además de ser uno de los elementos que lo distinguen de otras asociaciones de dos seres humanos y la base ojustificación de la presunción de paternidad de los hijos matrimoniales.

Es absurdo establecer los deberes esenciales de la institución mas vieja del mundo pensando en el procedimiento que le dará fin, ya que el proceso de disolución no puede fijar el contenido del instituto, que tiene perfiles propios por su propia conformación óntica y no por la forma variable y no esencial de su disolución.

Las estupefactas voces de la sorprendida doctrina jurídica argentina ante la inconsulta supresión del deber fundamental del matrimonio, conllevó a que este fuera agregado en el proyecto que los Dres. Highton Lorenzetti y Kemelmajer de Carlucci le entregaron a la Presidenta de la Nación Argentina el día 27 de 2012, en el Museo del Bicentenario. ${ }^{21}$

Llama la atención la escasa mención expresa a los deberes personales del matrimonio, cuando en otros contratos menos fundacionales de la sociedad, se hacen prolijas enumeraciones de los deberes personales de los contratantes.

Nos negamos a pensar que el matrimonio puede encerrar menos obligaciones personales que los contratos patrimoniales; lo que ocurre es que ellas se encuentran implícitas y son tácitas, y su no mención no las hace inexistentes. Así, por más que no se hable del deber de cohabitación o convivencia, éste es de la esencia matrimonial y es el que da sentido y fundamento a la protección de la vivienda familiar y a la determinación de la competencia judicial por el lugar donde se ubica la vivienda familiar o a la determinación del derecho aplicable en el ámbito del derecho internacional privado.

\footnotetext{
21 Axticulo $431^{\circ}$.- Asistencia. Los esposos se comprometen a desarrollar un proyecto de vida en común basado en la cooperación y el deber moral de fidelidad. Deben prestarse asistencia recíproca.
} 


\section{EL DIVORCIO INCAUSADO}

En relación con la disolución del matrimonio, desaparece la posibilidad de optar entre separación y divorcio, y se acepta al divorcio como única forma de dar fin al matrimonio. ${ }^{22}$

Lo mas importante en materia de divorcio es que se deja de lado la culpabilidad y la inocencia a la hora de establecer las consecuencias, impidiéndose valorar la conducta matrimonial al tiempo de la disolución, siendo absolutamente igualitario el trato que recibe quien atente, hiere, injuria, maltrata o tortura a su cónyuge, con quien se comporta con lealtad y respeto durante el régimen matrimonial.

Para divorciarse basta la voluntad de uno de los esposos, sin que se necesite que el otro esté de acuerdo, ni que se encuentren separados, ni el que haya pasado un tiempo desde que se celebró el matrimonio.

Se requiere solamente que se presente al juez una petición de divorcio con una propuesta que regule los efectos derivados de éste. En ningán caso, el desacuerdo con el convenio presentado unilateralmente suspende el dictado de la sentencia de divorcio. Es decir, que la oferta de convenio puede ser justo o injusto, equitativo o inequitativo y hasta abusivo, pero mientras que se presente, el divorcio se debe dictar y las partes seguirán discutiendo las consecuencias de la disolución del vínculo entre ellas la atribución de la vivienda familiar.

\section{LAS COMPENSACIONES ECONÓMICAS}

Se regulan las compensaciones económicas para la finalización del matrimonio tanto por divorcio como por nulidad y también para el cese de la unión convivencial. ${ }^{23}$

\footnotetext{
22 Sambrizzi, Eduardo (2012) La eliminación del doble régimen (separaçión personal y divorcio) y de las causales de divorcio y el llamado divorcio express. En: Reoista de Derecho de Familia y de Ins Personas - RDFyp, julio. Edición Especial: Análisis del Proyecto de Código Civil y Comercial de la Nación, p. 90; HOLLWECK, Mariana. Divorcio vincutar. Interpretacion de los arts. 437 y 438 del Froyecto, p. 73; SAVTESO, Javier (2012) Reforma al régimen de divorcio. En: Recrista del Derecho de Fanitia y de las Persontas -RDFyP, julio. Edición Especial: Análisis del Proyecto del Código Civil y Comercial de la Nacirin, g. 7; ROVEDA, Eduatdo G., SASSO, Marcela Lorena y ROBB, Mercedes. "El divorcio en el proyecto de Código Civil y Comercial", Revista citada p. 36; VELOSO, Sandra "El Proceso de divorcio según el Proyecto de Cóaigo Civil y Comercial" p. 45; CORBOA, Carlos María, "Analisis del Proyectoen materia de divorcio", p. 66.

2.3

Para un estudio más completo de las compensaciones económicas ver mi articulu Mattimonio y Disolución en este mismo libro fundamentalmente los puntos 17. La compensación económica. 17.1. Concepto de Compensación econónuca. 17.2. Pautas para fijar la compensación econónica. 17.3. Concepto de desequilibrio. 17.4. Forma de la compensación. 17.5. Desequilibrio perpetuo 17.6. Desequilibrio coyuntural. 17.7. Naturaleza de la Compensación económica.
} 
La compensación económica es un instituto nuevo en nuestro derecho y difiere de los alimentos que se deben los cónyuges, y de los daños y perjuicios.

La prestación compensatoria se fija a favor del cónyuge, o del conviviente a quien el divorcio o el cese de la unión convivencial, o el matrimonio anulado produce un desequilibrio manifiesto que signifique un empeoramiento de su situación, y que tiene por causa adecuada el vínculo matrimonial y su ruptura.

Reconoce como fundamento la solidaridad familiar y está destinada a lograr un equilibrio patrimonial; para lograrlo, es necesario realizar un análisis comparativo de la situación patrimonial de cada uno de los cónyuges al inicio del matrimonio y al momento de producirse el divorcio, esto es, obtener una "fotografia" del estado patrimonial de cada uno de ellos, y ante un eventual desequilibrio, proceder a su recomposición.

El monto y la duración de la prestación compensatoria la fija el juez teniendo encuenta:

a) el estado patrimonial de cada uno de los cónyuges o convivientes al inicio y a la finalización de la vida conjunta;

b) la dedicación que cada uno brindó a la familia y a la crianza y educación de los hijos durante la convivencia y la que debe prestar con posterioridad al divorcio;

c) la edad y el estado de salud de los cónyuges convivientes y de los hijos;

d) la capacitación laboral y la posibilidad de acceder a un empleo de quien solicita la compensación económica;

e) la colaboración prestada a las actividades mercantiles, industriales o profesionales del otro;

f) la atribución de la vivienda familiar, y si recae sobre un bien ganancial o común, un bien propio, un inmueble arrendado. En este último caso, quien abona el canon locativo. (Art. 442 y 525)

\section{LAUNIÓNCONVIVENCIAL. ${ }^{24}$}

Se regulan los efectos del concubinato al que se denomina unión convivencial, equiparándolo al matrimonio en todos los efectos personales y en varios de los efectos patrimoniales.

\footnotetext{
24 Pellegrini, Maria V. (2012)Las uriones convivenciales en el Proyecto de Código Civil, JA Número Especial: El Derecho de Familia en el Proyecto de Código Civil, p. 3; SOLARI, Néstor (2012) En. Revista de Derecho de la Fantilia y de las Personas - RDFyP, Jukio. Número Especial: Las uniones convivenciales en el Proyecto, p. 98.
} 
Como ya dijimos, la "unión convivencial" constituye un neologismo porque el término convivencial no existe en el Diccionario de la Real Academia Española.

Se deja de lado toda idea de libertad y de autonomía de la voluntad para poder vivir en forma conjunta, libremente y bajo la idea de que se hace por "solidaridad familiar"; se impone a quienes viven unidos de hecho, un régimen imperativo, legal y forzoso con severas consecuencias personales y patrimoniales.

Esta unión convivencial, no es necesaria que se registre, basta con dos años de convivencia para que produzca efectos jurídicos y si bien se prevé su registro, ella sólo es probatoria y no constitutiva.

Los convivientes pueden realizar pactos para regular sus relaciones patrimoniales; éstos son oponibles a terceros desde su registro; sino los hacen, se le aplica el régimen matrimonial de separación de hecho.

Se aplica a los convivientes un régimen primario igual al de los cónyuges en cuanto a sus responsabilidades, asistencia, contribución a los gastos del hogar, responsabilidad de las deudas frente a terceros (Art. 521) y protección de la vivienda familiar.

Es muy importante señalar que la vivienda familiar se transforma en inejecutable por deudas contraídas después del inicio de la unión convivencial (art. 522) lo que es extremadamente riesgoso para el tráfico jurídico porque la unión convivencial es una cuestión fáctica y normalmente el inmueble es la única garantía que tienen los acreedores quienes pueden ignorar la relación de convivencia de su deudor. Aunque el peligro se ve relativizado porque la unión convivencial debe ser registrada para que cause este efecto.

Por otra parte, al cese de la convivencia, la vivienda familiar puede ser atribuida a uno de los convivientes independientemente que sea el propietario del bien; esta atribución se encuentra limitada a dos años o al tiempo que ha durado la unión (si es inferior a los dos años), y a la muerte del propietario el conviviente supérstite tiene el derecho real de habitación gratuita por el término de dos años.

Ambos convivientes están obligados por el pago de las deudas del hogar, de los hijos comunes, y de los hijos menores de edad, o con capacidad restringida, o con discapacidad que conviven con ellos. 
Al cese de la convivencia, se establecen compensaciones económicas para el conviviente que sufre un desequilibrio manifiesto que signifique un empeoramiento de su situación económica con causa adecuada en la convivencia y su ruptura.

En definitiva, la única diferencia trascendente entre la unión convivencial y el matrimonio es que el segundo otorga a las partes calidad de herederos forzoso, mientras que el primero no; y que las nupcias tienen como régimen supletorio el de la comunidad, mientras que la convivencia tiene como régimen patrimonial supletorio el de separación de bienes, en lo demás son semejantes.

\section{EL PARENTESCO POR AFINIDAD}

En el proyecto se establece severas responsabilidades y grandes derechos a los parientes por afinidad en especial a los padres por afinidad.

Antes que nada, valga aclarar que bajo el nombre de parentesco por afinidad se regula lo que en doctrina se conoce como "familia ensamblada" o familia reconstituida".

Se entiende por "parentesco por afinidad", el que existe entre la persona casada y los parientes de su cónyuge. Así, el marido de la mujer divorciada con hijos de una primera unión, es el padre por afinidad de los niños de su esposa.

El parentesco por afinidad no crea vínculo jurídico alguno entre los parientes de uno de los cónyuges y los parientes del otro.

Cabe señalar que en principio, la unión convivencial no genera parentesco; sin embargo, se le impone al conviviente la denominación de progenitor afín y se le establecen iguales efectos que a los cónyuges.

Lo más importante del proyecto, es la obligación de cuidado y de alimentos que se atribuye obligatoriamente al padre afín a quien se le puede delegar parcial o totalmente la responsabilidad parental del hijo propio.

El cónyuge o conviviente de un progenitor debe cooperar en la crianza y educación de los hijos del otro, realizar los actos cotidianos relativos a su formación en el ámbito doméstico y adoptar decisiones ante situaciones de urgencia. 
Esta colaboración no afecta los derechos de los titulares de la responsabilidad parental.

En cuanto al deber alimentario, se dispone expresamente que el progenitor afín, tiene deber alimentario para con los hijos de su cónyuge o conviviente que en principio cesa con la finalización de la unión de su progenitor. Pero cuando el cambio de situación puede ocasionar un grave daño al niño o adolescente. Si el cónyuge o conviviente asumió durante la vida en común el sustento del hijo del otro, puede fijarse una cuota asistencial a su cargo con carácter transitorio, cuya duración debe definirla el juez de acuerdo a las condiciones de fortuna del obligado, las necesidades del alimentado y el tiempo de la convivencia.

Por otra parte, el progenitor afín tanto viva en unión convivencial como en matrimonio es solidariamente responsable con su cónyuge o conviviente por las deudas alimentarias del hijo no común menor de edad que conviva con la pareja ${ }^{25}$, tal como surge de las normas del régimen primario del matrimonio que se aplica también a las uniones convivenciales.

Además, en el régimen proyectado se legitima al progenitor por afinidad a reclamar daño moral por el daño sufrido por el hijo de su cónyuge (Art. 1741).

\section{LA FILIACIÓN POR VOLUNTAD PROCREACIONAL Y LA GESTACIÓN POR SUSTITUCIÓN}

Se establecen tres tipos de filiaciones: la filiación por naturaleza, la filiación adoptiva y la voluntad procreacional.

La gran novcdad del proyecto es la recepción de este tercer género de filiación que proviene de las técnicas de fecundación asistida y que hasta el momento no tenía una regulación general en el país.

La filiación, por naturaleza y por técnicas de fecundación asistida, se regula en forma conjunta mientras que la adopción se regula por separado.

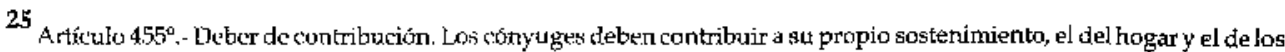
hijos comunes, en proporción a sus recursos. Esta obligaçión se extiende a las necesidades de los hijos mcnores de edad, o con capacidad restringida, o con discapacidad de mo de los cónyuges que conviver con ellos.

El cónyuge que no da cumplimiento a esta obligación puede ser demandado judicialmente por el otro para que lo haga. 
Estos tres tipos filiales (por naturaleza, por el uso de las técnicas de reproducción asistida y por adopción) tienen diferentes causas fuente (elemento biológico, voluntad procreacional y jurídico) a los fines de la determinación de la filiación y su consecuente sistema en materia de acciones, pero no respecto a sus efectos. De esta manera, se evita cualquier tipo de discriminación en razón del vínculo filial.

Al aceptar las técnicas de fecundación asistida como fuente filiatoria, el Proyecto del Código Civil se funda en el respeto a la autonomía de la voluntad, y más precisamente en el respeto a la autonomía de la voluntad procreacional, que permite y justifica tener un proyecto de vida referente y que viene ganando terreno en el Derecho de Familia a partir de la aceptación del matrimonio entre personas de igual sexo, con el cual cayó en el olvido una de las incapacidades fundantes del matrimonio cual era que para su celebración se requería diversidad sexual entre los contrayentes.

De la mano del matrimonio homosexual, surgieron los problemas derivados de la determinación de la filiación en los casos de matrimonios de lesbianas que daban a luz hijos mediante las técnicas de fecundación asistida. Estos problemas requerían de urgente regulación para evitar que la filiación de los niños dependiera de contradictorias decisiones judiciales.

Todas estas consideraciones llevaron a la necesidad de regular las técnicas de fecundación asistida y sus consecuencias, y el proyecto se inclinó por otorgarle naturaleza de fuente filiatoria.

Con relación a la filiación por voluntad procreacional los puntos más importantes son los correspondientes a la gestación por otro, al derecho a conocer la identidad y a la filiación póstuma. ${ }^{26}$

Dentro de la filiación por voluntad procreacional se acepta la maternidad por otro a la que se la denomina gestación por sustitución para desvincular a la madre de la gestante, reservando el término de mad̈re para la mujer que encarga el hijo, ya sea que aporte o no aporte el material genético.

\footnotetext{
26 Oppenheim, Ricardo (2012) Tratamiento del derecho a la identidad y a conocer los orígenes dado en el $\Gamma$ toyecto, p. 292; SOJO, Lorenzo, (2012) El anonimato de los donarites de gametos y embriones en el Rroyecto, p. 297, y Filiacion post mortem e n el Proyecto del Cádigo Civil y Comercial. En: Revista de Derecho de Fantilia y de las Personas - RDFyP. Juljo. Fdición Especial: Análisis del Proyecto de Código Civil y Comercial de la Nación; LAMM, Eleonora (201 2) Ta filiación derivada de las técnicas de Reproducción Asistida enel proyecto de Código, Cjvil, JA y El derecho de Familia enel Proyccto de Código Civil, p. 68 .
} 
La ley se aparta de la mayoría de las legislaciones del mundo que prohíben Ios contratos de gestación por otro y en cambio, lo regula con las condiciones que: éste sea gratuito, que la gestante no haya aportado el material genético, tenga ya un hijo y que no realice más de dos contratos de gestación por otro.

Con respecto a la gratuidad, hay que poner bien en claro que se refiere a la falta de una contraprestación por el embarazo por encargo, pero que de ninguna manera va a impedir el reembolso de los gastos y del lucro cesante, el que no puede entenderse como pago del precio para llevar adelante el embarazo.

En Grecia, uno de los pocos países que regula este contrato, se permite hasta el pago de 20.000 euros por concepto de gastos por el embarazo; mientras que en Inglaterra la jurisprudencia reconoce el pago de 10.000 libras por los gastos ocasionados por la gestación a los que hay que adicionarles el lucro cesante durante la gestación.

Nada se dice de las consecuencias que tiene el incumplimiento de los pactos que vienen asociados al contrato de gestación por sustitución, como es la cláusula de no fumar durante el embarazo o de no consumir drogas o de no tomar alcohol para no perjudicar al feto.

Cabe aclarar que hasta el momento estos convenios habian sido considerados nulos, por ser contrario a la moral y por tener un objeto prohibido cual es la disposición del cuerpo. Para evitar la sanción de nulidad por aplicación de las normas generales de los actos jurídicos, la legislación proyectada prevé la posibilidad de disposición y contratación sobre el cuerpo humano con fin afectivo, terapéutico, científico, humanitario o social, y la maternidad por otro encaja en los fines sociales. ${ }^{27}$

Estamos perfectamente de acuerdo en regular este tipo de filiación y también en la necesidad imperiosa de regular la filiación por gestación subrogada ya que la gestación por otro es posible y una vez nacido el niño, no se puede solucionar su problema diciendo que la criatura es nula porque el convenio

27 Artículo 17".- Derechos sobre cl cuerpo hutnano. Los dereshos sobre el cuerpo humano o sus partiss no tienen un valor económico, sino afectivo, terapético, cientffico, humanitario o social, $y$ solo pueden ser disponibles por su titular cuando se configure alguno de esos valores. 
que le dio origen es contrario al orden público. El nuevo ser necesita tener un vínculo filiatorio determinado con las personas que lo quieren. Ello se puede obtener por adopción o directamente otorgando validez filiatoria al convenio homologadojudicialmente.

En cuanto a la fecundación post morten ${ }^{28}$, se establece que en caso de muerte del cónyuge o conviviente de la mujer que da a luz, no hay vínculo filial entre la persona nacida del uso de las técnicas de reproducción humana asistida y la persona fallecida si la concepción en la mujer o la implantación del embrión en ella no se había producido antes del fallecimiento.

Se prevé que excepcionalmente puede haber vínculo filiatorio con el fallecido, si el hombre ha dado su consentimiento en un testamento y la implantación se produce dentro del año de su fallecimiento.

El tercero de los puntos más conflictivos en orden a la filiación por voluntad procreacional es el derecho al conocimiento de la realidad biológica que está contenido en la Convención de los Derechos del Niño y que en la filiación por adopción es un principio fundarte del instituto.

En la filiación por técnicas de fecundación asistida el derecho a conocer los orígenes es limitado. Así, el derecho de conocer la identidad genética con fines médicos es ilimitado cuando existan razones de salud, y el derecho a conocer la identidad del donante puede ser autorizado por autoridad judicial cuando existan motivos fundados y lógicamente sin que este conocimiento establezca filiación $^{29}$. La solución adoptada es valiosa porque respeta los recaudos de anonimato que son necesarios para realizar las técnicas, pero ante un conflicto de intereses de preponderancia siempre a la salud del hijo y cuando funde el hijo funde la necesidad del conocimiento y limita los alcances del anonimato por razones de equidad. Con lo cual, se logra un equilibrio que posibilita las técnicas y garantiza las necesidades del hijo estableciendo que ni el anonimato es iure et de iure, ni el derecho a conocer al aportante del material genético es absoluto.

\footnotetext{
28

Azpiri, Jorge (2012) La filiación en el Proyecto de Código Civil y Comercial. En: Revista de Derecho de Fanilia y de las Personas - RDFyp julio. Edición Especial: Análisis del Proyecto de Código Civil y Comercial de la Nacion, p. 115; SOJO, Lorenzu (2012) Filiacton post mortem en el Proyecto del Código Civil y Conercial. En: Revista de Derecho de Fumilia y de las Persontas-RDFyP, julio. Edición Especial: Análisis del Proyecto de Código Civil y Comencial de la Nación, p. 134. procedimiento más breve que prevea la ley local. Obtenerse del centro de salud ìnterviniente la información relativa a datos médicos del donante, cuando hay riesgo para la salud.
} 
Cabe destacar como una reforma importante en orden a la filiación la ampliación del número de los legitimados para impugnar la paternidad matrimonial, que ahora se denomina filiación matrimonial. En la legislación vigente los legitimados son el hijo y el marido, y le está vedada a la madre quien no puede aludir su propia torpeza, ni su adulterio, mientras que en la legislación proyectada se admite que la acción de impugnación de la filiación del o la cónyuge de quien da a luz, puede ser ejercida por éste o ésta, por el hijo, por la madre y por cualquier tercero que invoque un interés legítimo (Art. $590^{\circ}$ del Código Civil).

Otro tema altamente debatido en la actualidad es la validez a dar a la negativa a realizar las pruebas genéticas en los juicios de filiación. En este punto se establece claramente que el juez valorará la negativa como indicio grave contrario a la posición del renuente (Art. 579 ).

\section{EL RÉGIMEN PATRIMONIAL DEL MATRIMONIO}

En orden al régimen patrimonial del matrimonio las reformas más importantes son:

a) La posibilidad de optar entre el régimen de comunidad de bienes y el de separación de bienes.

b) El establecimiento de un régimen primario con obligaciones comunes a todos los regímenes, inderogable e inmodificable por voluntad de las partes.

c) La determinación de la inoponibilidad del acto realizado en fraude de los cónyuges durante la vigencia de la sociedad conyugal.

d) La regulación de la etapa de indivisión post comunitaria.

e) Detallada regulación de los bienes propios y gananciales tratando de dar respuesta legal a todas las cuestiones que durante años preocuparon a la jurisprudencia.

f) Aceptación de la teoría de las recompensas.

Es por eso que, en los fundamentos del proyecto se señala que "La mirada rigida sobre las relaciones humanas familiares, bajo la excusa de considerar todo el orden público, contraría la noción de pluralismo que pregona la doctrina internacional de los Derechos Humanos. En efecto, existe un derecho a la vida familiar $y$, consecuentemente, la injerencia estatal tiene límites". 
Estos fundamentos llevan a que en la legislación proyectada se pueda optar entre el régimen de comunidad de bienes y ganancias, y el régimen de separación de bienes como se proponía en el proyecto de 1998 y en el proyecto de 1993; aunque en este primer proyecto se preveía la posibilidad de optar entre tres regímenes en lugar de entre dos regímenes, siendo el tercero el régimen de participación en las ganancias.

\section{LA ADOPCIÓN}

El proyecto de Código Civil y Comercial de la Nación propone múltiples cambios en materia de adopción que en esta introducción no vamos a explicar; simplemente, los vamos a enumerar:

a) Incorporación de una parte general en materia de adopción con principios generales.

b) Definición limitada de uno de los cuatro tipos de adopción que acepta el Código. La adopción de menores. ${ }^{30}$

c) Regulación de cuatro tipos diferentes de adopción: de menores, de mayores, de integración y en el extranjero.

d) Fortalecimiento del derecho a conocer sus orígenes.

e) Establecimiento de cuatro procesos para llegar a la adopción. Uno administrativo y tres judiciales.

f) Administrativización de los procesos judiciales para lograr la adopción. Intervención en calidad de parte del órgano administrativo.

g) Regulación de la declaración de adoptabilidad.

h) El abandono deja de ser una causal de entrega en guarda con fines de adopción.

i) Los convivientes pueden adoptar conjuntamente.

j) Se permite la adopción conjunta por divorciados.

k) Se disminuye la edad para adoptar de treinta, a veinticinco años.

1) Sesuprime la condición de duración de tres años en el matrimonio.

m) Se suprime la esterilidad matrimonial para legitimar la adopción, sin la edad legal.

n) Se disminuye la diferencia de edad entre adoptante y adoptado de 18 a 16 años.

\footnotetext{
30 Para una mayor explicación de la Adoprión nos remitiruos a nuestro trabajo: La Adopción en el Código Civil y Comercial. Publicada en: Revista de Derecho Prizudo y Comunitario. Número decicado al Proyecto de Código Civil y Comercial. Ver también: BASSET, Lirsula (2012) Adopción en el Proyecto de Código Civil y Comercial, en: Revista de Derecho de Familia y de las Personas - RDFYP julio, p. 149; HERNÁNDEZ. Lidia B. (2012) Una primera mirada a la ínstitución de la adopción plena en el Proyecto", en: Rerista de Derecho de Familia y de las Personas - RDFyP. julio, p. 159; HERRERA, Marisa (2012) El régimen aúfoptivo en el Proyecto de Codigo Civil. Más sobre la trilogia. En: El derecho de Familia en el Proyecto de Código Civil, p. 84.
} 
o) El mayor de 10 años debe dar su consentimiento para ser adoptado.

p) Se regula la adopción de integración.

q) Regulación de las relaciones con la familia biológica.

r) Disminución del plazo de guarda con fines de adopción de un año a seis meses.

s) Aceptación relativa de las guarda de hecho.

t) Intervención judicial de oficio en juicio de adopción.

u) La adopción plena se relativiza y se mantienen los lazos con la familia de origen.

v) En la adopción plena se permite la investigación de la filiación biológica a los fines

de los impedimentos matrimoniales y de los derechos sucesorios.

w) Se regula la adopción internacional.

En materia de adopción el proyecto continúa con la tradición argentina en la materia de: por un lado disminuir tanto los requisitos objetivos que se requieren a los adoptantes, como el plazo de guarda con fines de adopción, al tiempo que aumenta los números de procesos judiciales para lograr la adopción y agrega procesos administrativos.

Objetivamente, no parece que con este aumento procedimental y administrativo se vaya a lograr dar más celeridad ni eficacia al instituto. No obstante lo cual, tenemos esperanzas que al aplicar las normas los operadores del derecho hagan primar el principio del interés superior del menor y optimicen los resultados, para bien de toda la comunidad, y en especial, de todos aquellos que tienen el corazón abierto a ser padres dar acogida amorosa a quienes tienen la necesidad imperiosa de una familia para desarrollarse. 


\section{EL PROCESO DE FAMILIA}

\subsection{Principios generales.}

En el proyecto, el Título VIII referido a los procesos de familia y en las disposiciones generales cita, en primer lugar, el principio de tutela judicial efectiva, que comprende el acceso a la justicia, el de economía y el de celeridad procesal, recogiéndose así el valor y entidad que se otorga a este principio en las 100 Reglas de Brasilia sobre acceso a la Justicia en condiciones de vulnerabilidad, ${ }^{31}$ todo en relación directa con los principios de inmediación, buena fe, lealtad procesal, oficiosidad y oralidad.

En este Título, el Proyecto contiene una serie de reglas aplicables a los procesos de familia entre las que se encuentra las de impulso procesal de acceso al proceso, legitimación, oralidad, anticipo de prueba, agilidad, prioridad, coordinación, especialización, actuación interdisciplinaria, proximidad, estímulo de las formas alternativas de resolución de conflictos; promoción de actuaciones destinadas a proporcionar una información básica sobre los derechos.

Se busca la aplicación del principio de agilidad o celeridad en todas las fases del procedimiento, así como en la propia ejecución. La eficacia exige rapidez en la respuesta pues, como expresa el aforismo, "justice delayed is justice denied".

\subsection{Competencia.}

En el capítulo III del Título VIII se establecen normas sobre la competencia, determinando que en los procesos relativos a los derechos de niños, niñas y adolescentes es juez competente aquel donde el menor de edad tiene su centro de vida. En los de divorcio o en los de uniones convivenciales, el juez del domicilio conyugal o el del demandado, a elección del actor. En el de

${ }^{31}$ Declaración de Brasilia XIV Cumbre Judicial tberoamericana. Realizada el 4,5 Y 6 de marzo de 2008. 
alimentos y pensiones compensatorias, el juez del domicilio conyugal o convivencial, el del beneficiario o el del demandado a elección del actor.

\section{Conclusión}

A lo largo de este artículo hemos tratado de describir los aspectos más trascendentes de las grandes reformas introducidas al Derecho de Familia por el Proyecto de Código Civil Unificado, las que necesariamente deben, por un lado, ser discutidas por la comunidad jurídica para lograr un mínimo de consenso en su utilidad y necesidad; y por otra parte, deben ser armonizadas con todo el ordenamiento proyectado para evitar inútiles contradicciones que produzcan dudas en su alcance y problemas en su aplicación evitando que generen inútiles injusticias para sus destinatarios.

\section{REFERENCIAS}

Azpiri, Jorge (julio 2012) La filiación en el Proyecto de Código Civil y Comercial En: Revista de Derecho de Familia y de las Personas - RDFyP,. Edición Especial: Análisis del Proyecto de Código Civil y Comercial de la Nación.

Cerra, Silvana, (2010) Calificación y prueba de los bienes. Aplicación a un supuesto especial: adquisición de un inmueble mediante el empleo de fondos de carácter propio y ganancias, En: Revista de Derecho de familia y de las Personas $-R D F y P$.

Basset, Ursula (julio 2012 ) Adopción en el Proyecto de Código Civil y Comercial, En: Revista de Derecho de Familia y de las Personas-RDFyP.

Berbere Delgado, Jorge (julio 2012) El Derecho Filial en el proyecto de Código Civil y Comercial - Nuevos paradigmas En: Revista de Derecho de Familia y de las Personas $-R D F y$ E Edición Especial: Análisis del Proyecto del Código Civil y Comercial de la Nación.

Borda, Guillermo (julio 2012) Las relaciones de familia en el proyecto del Código Civil y Comercial, En: Revista de Derecho de la Familia y de las Personas RDFyP. 
Cañivano, Miguel Angel (2002) El covenant marriage como alternativa a los non fault divorces" , En: Revista de Derecho Privado.

Chiesa, Pedro José María, (2010) El derecho a la protección constitucional de las opciones matrimoniales definitivas, Tesis doctoral, Universidad Nacional de Córdoba, Córdoba.

Hernández, Lidia B. (julio 2012,) Una primera mirada a la institución de la adopción plena en el Proyecto, En: Revista de Derecho de Familia y de las Personas - RDFyP.

Laje, Alejandro (julio 2012) Las derivaciones inmediatas y mediatas del vínculo materno-filial por el Proyecto En: Revista de Derecho de Familia y de las Personas RDFyP, Edición Especial: Análisis del Proyecto del Código Civil y Comercial de la Nación.

Mizrahi, Mauricio Luis. (julio 2012) "Observaciones al Proyecto en materia de filiación" En: Revista de Derecho de Familia y de las Personas- RDFyP Edición Especial Análisis del Proyecto del Código Civil y Comercial de la Nación. Pág. 124.

Sambrizi, Eduardo (julio 2012) La eliminación del doble régimen (separación personal y divorcio) y de las causales de divorcio, y el llamado divorcio express En: Revista de Derecho de Familia y de las Personas -RDFyP, Edición Especial: Análisis del Proyecto de Código Civily Comercial de la Nación.

Santiso, Javier (julio 2012) Reforma al régimen de divorcio. En: Revista del Derecho de Familia y de las Personas -RDFyP, Edición Especial: Análisis del Proyecto del Código Civil y Comercial de la Nación.

Sojo, Lorenzo (julio 2012) Filiación post mortem en el Proyecto del Código Civil y Comercial En: Revista de Derecho de Familia y de las Personas - RDFyP, Edición Especial: Análisis del Proyecto de Código Civil y Comercial de la Nación. 
